\title{
Modified and Alternative Baveno VI Criteria Based on Age for Ruling Out High-risk Varices in Patients With Compensated Cirrhosis
}

\section{Lili Zhao}

Tianjin City Second People's Hospital

\section{Ting Wang}

Zhejiang University

Chunxia Guo

Tianjin City Second People's Hospital

\section{Li Zhou}

Tianjin City Second People's Hospital

\section{Ping Han}

Tianjin City Second People's Hospital

\section{Chunyan Wang}

Tianjin City Second People's Hospital

\section{Ying Ma}

Tianjin City Second People's Hospital

\section{Jing Wang}

Tianjin City Second People's Hospital

\section{Min Gao}

Tianjin City Second People's Hospital

Jia Li (D 18622663700@163.com)

Tianjin City Second People's Hospital https://orcid.org/0000-0003-0100-417X

\section{Research Article}

Keywords: liver cirrhosis, high-risk varices, age, ultrasound, liver stiffness

Posted Date: March 1st, 2022

DOI: https://doi.org/10.21203/rs.3.rs-1352816/v1

License: (1) (1) This work is licensed under a Creative Commons Attribution 4.0 International License.

Read Full License 


\section{Abstract}

Background: The Baveno VI criteria(B6C) was recommended to screen high-risk varices(HRV) in liver cirrhosis patients so that esophagogastroduodenoscopy(EGD) could be safely avoided. It was perceived as conservative, and Transient elastography is not available in many medical institutions; this restricts the clinical application of $\mathrm{B} 6 \mathrm{C}$. We aimed to optimize the $\mathrm{B} 6 \mathrm{C}$ to screen more patients who could safely avoid screening EGD and to explore the parameters to replace liver stiffness $(\mathrm{LS})$.

Methods: 1188 patients with compensated cirrhosis were analyzed and divided into the training cohort(TC) and validating cohort(VC) by the split-sample method. Variables were selected to construct the new criteria in the TC and were validated in the VC.

Results: Age $\geq 50$ years, LS, platelet count(PLT), and spleen area (SA) were independently associated with HRV. The risk of HRV was 2.39 times higher in patients over 50 years, so the alternative $B 6 C(A B 6 C)$ and modified $\mathrm{B} 6 \mathrm{C}(\mathrm{MB} 6 \mathrm{C})$ criteria were built based on age. MB6C was built by adjusting the cutoff value of $\mathrm{LS}$ and PLT (patients aged $<50$ years, the criteria of PLT $>100 \times 10^{9} / \mathrm{L}$ and $\mathrm{LS}<30 \mathrm{kPa}$; aged $\geq 50$ years, combination of $\mathrm{PLT}>125 \times 10^{9} / \mathrm{L}$ and $\mathrm{LS}<20 \mathrm{kPa}$ ). The predicting performance HRV showed no statistical difference between PLT, SA and LS. SA was selected to replace the LS and built AB6C(patients aged $<50$ years, the criteria of $\mathrm{PLT}>100 \times 10^{9} / \mathrm{L}$ and $\mathrm{SA}<55 \mathrm{~cm}^{2}$; aged $\geq 50$ years, combination of $\mathrm{PLT}>125 \times 10^{9} / \mathrm{L}$ and $\mathrm{SA}<44 \mathrm{~cm}^{2}$ ).

Conclusions: The excellent performance of $\mathrm{MB} 6 \mathrm{C}$ and $\mathrm{AB} 6 \mathrm{C}$, which stratified by age, were validated for safely ruling out high-risk varices and these could help avoid more EGD procedures than B6C and EB6C.

\section{Clinical trial registration number: ChiCTR-DDD-17013845.}

\section{Introduction}

Gastroesophageal variceal hemorrhage is one of the most serious decompensation events that directly affects the survival rate of patients ${ }^{[1]}$. Therefore, international guidelines ${ }^{[2]}$ state that "All cirrhotic patients should be screened for varices at diagnosis." However, the prevalence of high-risk varices (HRV) is only $16 \%$ in a population of wellcompensated patients ${ }^{[3]}$. Considering the invasiveness and low acceptance of esophagogastroduodenoscopy (EGD) in patients, it is necessary to conduct non-invasive methods to evaluate and screen varices.

The 2015 Baveno VI Conference consensus proposed the combination of platelet count (PLT) and liver stiffness (LS) to screen and detect high-risk varices (Baveno VI criteria, B6C ${ }^{[4]}$. Patients with compensated liver cirrhosis (CLC) meeting the criteria (LS $<20 \mathrm{kPa}$ and PLT $>150 \times 10^{9} / \mathrm{L}$ ) could avoid undergoing EGD since their risk of developing HRV was very low ( $<5 \%$ is perceived as acceptable). Although the validation showed that B6C worked well and could prevent $16-33 \%$ of EGD ${ }^{[5-7]}$, it was perceived as conservative. The expanded Baveno VI criteria (EB6C) $\left(\mathrm{PLT}<110 \times 10^{9} / \mathrm{L}\right.$ and LS $>25 \mathrm{kPa}$ ) 
could avoid up to $40 \%$ of $\mathrm{EGDs}^{[8]}$. In the verification process of $\mathrm{B} 6 \mathrm{C}$ and $\mathrm{EB} 6 \mathrm{C}$, inconsistent conclusions were drawn for the etiological differences between the validation cohorts ${ }^{[9-11]}$. However, since there is limited validation research in an Asian cohort with Hepatitis B, it is necessary to further verify and optimize the B6C in a large-scale cohort.Transient elastography (TE), which is used to measure LS is not available in many medical institutions, this restricts the clinical application of B6C. Alternative indicators of LS are needed. At the same time, with the increasing non-invasive methods for evaluating fibrosis, more patients are being diagnosed with early cirrhosis. Therefore, it is necessary to optimize the B6C to rule out patients who can safely avoid screening EGD.

We aimed to: 1. identify the risk factors of HRV and optimize the B6C (modified Baveno VI criteria, MB6C); 2. build the easy-to-use criteria without LS (alternative Baveno VI criteria, AB6C) to make the recommendation of HRV screening more accurate and reasonable; 3. compare the performance of the $\mathrm{MB} 6 \mathrm{C}$ and $\mathrm{AB} 6 \mathrm{C}$ with the $\mathrm{B} 6 \mathrm{C}$ and $\mathrm{EB} 6 \mathrm{C}$.

\section{Patients And Methods}

\section{Patient selection}

This study has been approved by the ethics committee of the Tianjin Second People's Hospital and has been performed in accordance with the ethical standards laid down in the 1964 Declaration of Helsinki and its later amendments. The informed consent was obtained and details that might disclose the identity of the subjects under study have been omitted. Clinical data of inpatients with CLC were analyzed from January of 2016 to December of 2019 (clinical trial registration number: ChiCTR-DDD-17013845).

The inclusion criteria were: 1.eighteen to eighty years of age; 2. patients with an irregular and nodular liver, along with impaired liver synthetic function, who were diagnosed with cirrhosis using imaging (ultrasonography, computed tomography, or magnetic resonance imaging) ${ }^{[13]} ; 3$. the absence of previous decompensated complications of cirrhosis including ascites, hepatic encephalopathy, or gastroesophageal variceal hemorrhage; 4 . patients who had all their latest data ( $\leq 3$ months old): EGD, Fibroscan, imaging, and laboratory examinations done $\leq 3$ months prior.

The exclusion criteria were cases of: 1 . decompensated cirrhosis; 2 . primary prevention using nonselective $\beta$-blockers or endoscopic ligation; 3. portal vein thrombosis; 4 . non-cirrhotic portal hypertension; 5. splenectomy or congenital absence of the spleen; 6 . transjugular intrahepatic portosystemic shunt procedure performed on the patient; 7. hepatocellular carcinoma; 8. liver transplantation; 9. incomplete clinical data.

\section{Patient evaluation}

EGD 
The EGD was performed by two experienced operators using the Olympus CV-260SLprocessor (Olympus medical imaging, Osaka, Japan). The varices were described according to the expert guideline ${ }^{[14]}$. According to the guideline ${ }^{[5]}, \mathrm{HRV}$ was defined as varices with a diameter $\geq 5 \mathrm{~mm}$ or which were red sign positive, requiring non-selective beta-blockers (NSBB) or ligation for preventing bleeding.

\section{Transient elastography}

The measurement of LS by transient elastography, using Fibroscan 520 (Echosens, Paris, France), was done by two experienced practitioners with professional training. The patients were in a fasting state in the morning and were placed in a supine position, with the right arm in maximum abduction to make the right lobe of the liver accessible during operation. Ten measurements were obtained with a success rate of $60 \%$ and an interquartile range of less than $30 \%$.

\section{Spleen size}

Patients routinely underwent abdominal ultrasound examinations to measure the spleen size. The spleen diameter and thickness (measured across the spleen hilum) were reported and recorded for calculating the spleen area (SA = diameter multiplied by thickness) according to the published guidelines ${ }^{[15]}$. The patients fasted overnight. Ultrasound was then performed by professional operators who did not know the clinical details of the patients.

We collected demographic, clinical, and laboratory data.

\section{Statistical analysis}

Statistical analysis was performed using SPSS 20.0 package (IBM SPSS, Chicago, IL). Continuous data were represented by the median (interquartile range), and categorical variables by proportions. The chisquare test or Mann-Whitney $U$ test was used for group comparisons of categorical and continuous variables. The entire cohort was divided into a training cohort (TC) $(n=583)$ and a validation cohort (VC) $(n=605)$ by the split-sample method. Variables found to be significant in the univariate analysis $(P<0.05)$ were included in a multivariable logistic regression (a forward selection approach for stepwise regression) in the TC. The predicting performance of non-invasive indicators for HRV was assessed by a receiver operating curve (ROC) analysis. Sensitivity (SE), specificity (SP), and negative predictive value (NPV) were calculated for each criterion under different age stratifications.

\section{Results}

\section{General characteristics}

Overall, A total of 1188 participants were included in the study with 583 and 605 participants for the TC and $\mathrm{VC}$, respectively. Flow chart for participant inclusion/exclusion are provided in Fig. 1. The clinical characteristics of patients in the TC and VC are listed in Table 1. The median age of patients in the global cohort was 52 (25th to 75th percentiles, 42-59) years, among whom 701 (59.0\%) were male, 1068 
(89.9\%) was Child-Pugh A class, 576 (48.5\%) had varices, and 146 (12.3\%) had HRV. The most common cause of cirrhosis was hepatitis B virus infection, which was found in 415 of the 583 patients $(71.2 \%)$ in the TC and in 446 of the 605 participants (73.7\%) in the VC. The VC had similar baseline characteristics to the TC. There was no statistical difference between the TC and VC. Comparison of patients with and without HRV in the entire cohort is also displayed in Supporting Table S1.

Table 1

General characteristics and comparison of TC and VC

\begin{tabular}{|lllll|}
\hline Variable & All & TC & VC & Pvalue \\
& $(\mathbf{n = 1 1 8 8 )}$ & $(\mathbf{n = 5 8 3})$ & $(\mathbf{n = 6 0 5 )}$ & \\
\hline Age,years & $52(42,59)$ & $52(42,59)$ & $52(41,60)$ & 0.791 \\
\hline Man, $\mathrm{n}(\%)$ & $701,(59.0)$ & $355,(60.9)$ & $346,(57.2)$ & 0.195 \\
\hline BMI, Kg/m & $24.9(22.8,27.3)$ & $25.0(22.9,27.4)$ & $24.8(22.7,27.3)$ & 0.250 \\
\hline Etiology, $\mathrm{n}(\%)$ & - & - & - & 0.552 \\
\hline HBV & $861,(72.5)$ & $415,(71.2)$ & $446,(73.7)$ & - \\
\hline HCV & $169,(14.2)$ & $89,(15.3)$ & $80,(13.2)$ & - \\
\hline Non-viral infectious & $158,(13.3)$ & $79,(13.5)$ & $79,(13.1)$ & - \\
\hline C-P A, $n(\%)$ & $1068,(89.9)$ & $530,(90.9)$ & $538,(88.9)$ & 0.257 \\
\hline ALT, U/L & $49(26,118)$ & $48(26,113)$ & $49(25,125)$ & 0.742 \\
\hline AST, U/L & $45(26,102)$ & $44(26,97)$ & $47(26,111)$ & 0.292 \\
\hline ALB, g/L & $43.1(39.0,46.2)$ & $43.5(39.4,46.1)$ & $42.8(38.8,46.4)$ & 0.189 \\
\hline TBIL, $\mu$ mol/L & $17.4(13.1,24.6)$ & $17.4(13.2,23.9)$ & $17.3(13.1,25.7)$ & 0.753 \\
\hline INR & $1.05(1.00,1.14)$ & $1.05(1.00,1.13)$ & $1.05(1.00,1.15)$ & 0.666 \\
\hline PLT, $\times 10^{9} / L$ & $135(98,174)$ & $135(101,174)$ & $135(98,172)$ & 0.514 \\
\hline LS, kPa & $14.3(8.8,24.5)$ & $14.0(8.8,25.7)$ & $15.0(9.0,23.6)$ & 0.369 \\
\hline SA, cm ${ }^{2}$ & $42.94(34.65,56.25)$ & $42.56(33.95,56.25)$ & $43.32(35.12,55.90)$ & 0.460 \\
\hline Varices, $n(\%)$ & $576,(48.5)$ & $282,(48.4)$ & $294,(48.6)$ & 0.938 \\
\hline HRV, $n(\%)$ & $146,(12.3)$ & $69,(11.8)$ & $77,(12.7)$ & 0.64 \\
\hline
\end{tabular}

Abbreviations: TC, Training cohort; VC, Validating cohort; HRV, High-risk varices; BMI, Body mass index; HBV, Hepatitis B virus; HCV, Hepatitis C virus; C-P, Child-Pugh class; ALT, Alanine aminotransferase; AST, Aspartate aminotransferase; ALB, Albumin; TBIL, Total bilirubin; INR, International normalized ratio; PLT, Platelet count; LS, Liver stiffness; SA, Spleen area 


\section{Predictors of HRV in the TC}

The univariate analysis was performed to detect the variables associated with the presence of HRV.

Table 2 showed that the variables age, Albumin, total bilirubin, international normalized ratio, PLT, LS, and SA were significantly different (all $P<0.05$ ). The ROC analysis showed that the area under the receiver operating characteristic (AUROC) of age was 0.605 (95\% confidence interval [Cl]: $0.564-0.645$ ), and the best cut-off value was 52 years of age. To create an "easy-to-use" algorithm, 50 years of age was selected for the risk stratification. Age was evaluated as dichotomous data in the multivariate analysis. The risk of HRV in patients over 50 years was 2.387 times those under 50 years of age (Fig. 1-A).

Table 2

Predictors of HRV in TC

\begin{tabular}{|c|c|c|c|c|c|}
\hline \multirow[t]{2}{*}{ Variables } & \multicolumn{3}{|l|}{ Univariate analysis } & \multicolumn{2}{|c|}{ Multivariate analysis } \\
\hline & HRV +(n = 69) & HRV -(n = 514) & $\begin{array}{l}P \\
\text { value }\end{array}$ & OR, 95\% Cl & Pvalue \\
\hline Age,years & $55(48,62)$ & $51(41,58)$ & 0.004 & - & - \\
\hline $\begin{array}{l}\text { Age } \geq 50, n \\
(\%)\end{array}$ & 49(71.0) & $287(55.8)$ & 0.017 & $\begin{array}{l}2.387,1.282- \\
4.443\end{array}$ & 0.006 \\
\hline Man, n (\%) & $43(62.3)$ & $312(60.7)$ & 0.796 & - & - \\
\hline $\mathrm{BMI}, \mathrm{kg} / \mathrm{m}^{2}$ & $24.9(22.9,27.6)$ & $25.0(22.9,27.3)$ & 0.964 & - & - \\
\hline C-P A, n (\%) & 63,(91.3) & 467, (90.9) & 0.903 & - & - \\
\hline ALT, U/L & $42(27,77)$ & $49(26,119)$ & 0.258 & - & - \\
\hline AST, U/L & $52(28,92)$ & $44(26,99)$ & 0.515 & - & - \\
\hline ALB, $g / L$ & $40.7(37.4,45.4)$ & $43.7(39.8,46.3)$ & 0.002 & - & - \\
\hline TBIL, $\mu \mathrm{mol} / \mathrm{L}$ & $18.9(15.3,27.1)$ & $17.1(12.9,23.6)$ & 0.017 & - & - \\
\hline INR & $1.11(1.05,1.27)$ & $1.04(0.99,1.12)$ & $<0.001$ & - & - \\
\hline $\mathrm{PLT}, \times 10^{9} / \mathrm{L}$ & $85(65,116)$ & $141(108,179)$ & $<0.001$ & $\begin{array}{l}0.986,0.979- \\
0.993\end{array}$ & 0.000 \\
\hline LS, kPa & $27.0(16.9,36.8)$ & $13.1(8.3,21.6)$ & $<0.001$ & $\begin{array}{l}1.034,1.014- \\
1.053\end{array}$ & 0.001 \\
\hline $\mathrm{SA}, \mathrm{cm}^{2}$ & $59.04(47.18,72.8)$ & $41.19(32.99,53.75)$ & $<0.001$ & $\begin{array}{l}1.018,1.003- \\
1.033\end{array}$ & 0.017 \\
\hline
\end{tabular}

Abbreviations: HRV, High-risk varices; TC, Training cohort; OR, Odds ratio; Cl, Confidence interval; $\mathrm{BMI}$, Body mass index; C-P, Child-Pugh class; ALT, Alanine aminotransferase; AST, Aspartate aminotransferase; ALB, Albumin; TBIL, Total bilirubin; INR, International normalized ratio; PLT, Platelet count; LS, Liver stiffness; SA, Spleen area. 
Multivariateanalysis showed that age $\geq 50$ years, LS, PLT, and SA were independently associated with HRV (Supporting Table S4). In the TC, the predicting performance of PLT, SA and LS for HRV was assessed by a receiver operating curve (ROC) analysis. The AUROC of PLT, SA and LS were 0.781 ([CI]: $0.745-0.814$ ), 0.731 ([Cl]: 0.694-0.767), and 0.735 ([Cl]: 0.697-0.770), respectively. The Delong test showed that there was no statistical difference between PLT, SA, and LS (Fig. 1-B). Therefore, SA could replace LS to establish a new criterion to predict HRV.

\section{The modified Baveno VI criteria based on age stratification}

Table 3 shows the performance of the exploratory data and the new age-based criteria by adjusting the cutoff value of LS and PLT in each age-related subgroup. In patients $<50$ years of age, the criteria of PLT $>100 \times 10^{9} / \mathrm{L}$ and $\mathrm{LS}<30 \mathrm{kPa}$ maximized the number of potential EGDs that were avoided while keeping the risk of missing a HRV below the $5 \%$ threshold. For patients aged $\geq 50$ years, the same result was obtained with a combination of PLT $>125 \times 10^{9} / \mathrm{L}$ and $\mathrm{LS}<20 \mathrm{kPa}$. We have named these new classification rules the MB6C.

Table 3

Performance of the exploratory data and MB6C and AB6C classification rules based on age in the TC

\begin{tabular}{|c|c|c|c|c|c|c|}
\hline & & $\begin{array}{l}\text { Patients age } \\
(n=247)\end{array}$ & & & $\begin{array}{l}\text { Patients age } \\
(n=336)\end{array}$ & \\
\hline Variables & & $\begin{array}{l}\text { EGD spared, } \\
\mathrm{n},(\%)\end{array}$ & $\begin{array}{l}\text { HRV missed, } \\
\mathrm{n},(\%)\end{array}$ & & $\begin{array}{l}\text { EGD spared, } \\
\mathrm{n},(\%)\end{array}$ & $\begin{array}{l}\text { HRV missed, } \\
\mathrm{n},(\%)\end{array}$ \\
\hline PLT & $>115$ & $171(69.2)$ & $3(1.8)$ & $>125$ & 179 (53.3) & $12(6.7)$ \\
\hline & $>110$ & 175 (70.9) & $3(1.7)$ & $>120$ & $192(57.1)$ & $13(6.8)$ \\
\hline & $>100$ & $193(78.1)$ & $3(1.6)$ & $>115$ & $207(61.6)$ & $14(6.8)$ \\
\hline LS & $<30$ & $204(82.6)$ & $9(4.4)$ & $<25$ & $251(74.7)$ & $23(9.2)$ \\
\hline & $<25$ & $182(73.7)$ & $5(2.7)$ & $<20$ & $217(64.6)$ & $18(8.3)$ \\
\hline & $<20$ & $164(66.4)$ & $4(2.4)$ & - & - & - \\
\hline SA & $<55$ & $172(69.6)$ & $6(3.5)$ & $<55$ & $249(74.1)$ & $21(8.4)$ \\
\hline & $<50$ & $155(62.8)$ & $3(1.9)$ & $<50$ & $222(66.1)$ & $17(7.7)$ \\
\hline & $<44$ & $125(50.6)$ & $2(1.6)$ & $<44$ & $178(53.0)$ & $11(6.2)$ \\
\hline MB6C & $\begin{array}{l}\mathrm{PLT}>100 \\
+\mathrm{LS}<30\end{array}$ & $171(69.2)$ & $1(0.6)$ & $\begin{array}{l}\mathrm{PLT}>125 \\
+\mathrm{LS}<20\end{array}$ & $145(43.2)$ & $6(4.1)$ \\
\hline$A B 6 C$ & $\begin{array}{l}\text { PLT > } 100 \\
+ \text { SA }<55\end{array}$ & $158(64.0)$ & $3(1.9)$ & $\begin{array}{l}\mathrm{PLT}>125 \\
+\mathrm{SA}<44\end{array}$ & $129(38.4)$ & $6(4.7)$ \\
\hline
\end{tabular}


Abbreviations: MB6C, Modified Baveno VI criteria;AB6C, Alternative Baveno VI criteria; HRV,High-risk varices; TC, Training cohort; EGD, Esophagogastroduodenoscopy; PLT, Platelet count $\left(\times 10^{9} / \mathrm{L}\right)$; LS, Liver stiffness $(\mathrm{kPa})$; SA, Spleen area $\left(\mathrm{cm}^{2}\right)$.

We tested the MB6C in the VC (Table 4). In the patients < 50 years of age $(n=269), 187(69.5 \%)$ met the MB6C, among whom $3(1.6 \%)$ had HRV. In patients age $\geq 50,123(36.6 \%)$ met the MB6C and $4(3.3 \%)$ among them had HRV. Totally, MB6C could help avoid EGD in $310(51.2 \%)$ patients with $7(2.3 \%)$ cases of HRV that were missed.

Table 4

Performance of the MB6C and AB6C in the VC

\begin{tabular}{|c|c|c|c|c|c|c|}
\hline & \multicolumn{2}{|c|}{$\begin{array}{l}\text { VC } \\
(n=605)\end{array}$} & \multicolumn{2}{|c|}{$\begin{array}{l}\text { Patients age }<50 \\
(n=269)\end{array}$} & \multicolumn{2}{|c|}{$\begin{array}{l}\text { Patients age } \geq 50 \\
(n=336)\end{array}$} \\
\hline & $\begin{array}{l}\text { EGD } \\
\text { spared, } \\
\text { n, (\%) }\end{array}$ & $\begin{array}{l}\text { HRV missed, n, } \\
(\%)\end{array}$ & $\begin{array}{l}\text { EGD } \\
\text { spared, } \\
\mathrm{n},(\%)\end{array}$ & $\begin{array}{l}\text { HRV missed, } n \text {, } \\
(\%)\end{array}$ & $\begin{array}{l}\text { EGD } \\
\text { spared, } \\
\mathrm{n},(\%)\end{array}$ & $\begin{array}{l}\text { HRV missed, } n \text {, } \\
(\%)\end{array}$ \\
\hline MB6C & $\begin{array}{l}310 \\
(51.2)\end{array}$ & $7(2.3)$ & $\begin{array}{l}187 \\
(69.5)\end{array}$ & $3(1.6)$ & $\begin{array}{l}123 \\
(36.6)\end{array}$ & $4(3.3)$ \\
\hline $\mathrm{AB} 6 \mathrm{C}$ & $\begin{array}{l}297 \\
(49.1)\end{array}$ & $8(2.7)$ & $\begin{array}{l}174 \\
(64.7)\end{array}$ & $2(1.1)$ & $\begin{array}{l}123 \\
(36.6)\end{array}$ & $6(4.9)$ \\
\hline
\end{tabular}

Abbreviations: MB6C, Modified Baveno VI criteria; AB6C, Alternative Baveno VI criteria; HRV: High-risk varices; VC, Validating cohort; EGD,Esophagogastroduodenoscopy;

\section{Construct the alternative criteria based on age stratification}

The SA was selected to replace the LS and build the AB6C. In patients $<50$ years of age, thecriteriaof PLT $>100 \times 10^{9} / \mathrm{L}$ and $\mathrm{SA}<55 \mathrm{~cm}^{2}$ maximized the number of potential EGDs avoided while keeping the risk of HRV missed below $5 \%$. In patients aged $\geq 50, A B 6 C$ was the combination of $P L T>125 \times 10^{9} / L$ and $S A<44$ $\mathrm{cm}^{2}$ (Table 3).

The performance of $A B 6 C$ in the $V C$ is shown in Table 4. 174 (67.4\%) cases met the AB6C for the subgroup age $<50(n=269)$, among them $2(1.1 \%)$ had HRV. The alternative criteria for the subgroup age $\geq 50$ was met by 123 (36.6\%)cases, among them 6 (4.9\%) had HRV. Overall, the AB6C could avoid 297 (49.1\%) EGDs with 8 (2.7\%) cases of HRV that were missed.

\section{Validation of the $\mathrm{B} 6 \mathrm{C}, \mathrm{EB} 6 \mathrm{C}, \mathrm{MB} 6 \mathrm{C}$, and $\mathrm{AB} 6 \mathrm{C}$, and a comparison of the different criteria}

In the entire cohort $(n=1188), 377(31.7 \%)$ patients met the B6C. Of these 377 patients, $245(64.9 \%)$ had no varices, $126(33.4 \%)$ were low-risk varices (LRV) (diameter $\leq 5 \mathrm{~mm}$ ), and only $6(1.6 \%)$ had HRV. Among the 651 (54.8\%) patients that met the EB6C, 402 (61.8\%) did not have varices, $225(34.6 \%)$ had LRV, and 24 (3.7\%) had HRV (Supporting Table S2). 
Next, we evaluated the performance of these criteria in the entire cohort and age-related subgroups (Supporting Table S2 and S3). In patients $<50$ years of age $(n=516)$, the B6C, EB6C, and MB6C could safely help avoid $36.8 \%, 59.1 \%$, and $69.4 \% E G D s$, respectively. In patients $\geq 50$ years of age $(n=672), B 6 C$ could safely avoid $27.8 \%$ of EGDs with the risk of missing HRV being $<5 \%$. Although the EB6C could avoid more EGDs (51.5\%), $6.4 \%$ of HRV were missed. The MB6C could not only avoid more EGDs (39.9\%) than B6C (27.8\%), but also keep a low risk of missing HRV (3.7\%). Overall, in the entire cohort, the MB6C helped avoid $52.7 \%$ of potential EGDs, and only $2.2 \%$ HRV were missed

Besides, $\mathrm{AB} 6 \mathrm{C}$ also had a good performance in the entire cohort. By using the corresponding $\mathrm{AB} 6 \mathrm{C}$ in the patients $<50(n=516)$ and $\geq 50$ years of age $(n=672), 64.3 \%$ and $37.5 \%$ of the patients, respectively, could avoid EGD with $1.5 \%$ and $4.8 \%$ HRV being missed. Overall, the AB6C could safely spare $49.2 \%$ EGDs with only2.9\% HRV being missed(Fig. 3).

\section{Discussion}

In this study, we proposed and validated a new screening criterion of HRV based on age-stratification in patients with compensated liver cirrhosis. First, similar to Berger $A$ et al. ${ }^{[17]}$, we found that the prevalence of HRV was $12.3 \%$ in the entire cohort. However, the risk of HRV increased significantly with age $(15.9 \%$ in patients $\geq 50$ years of age), while it decreased to $7.6 \%$ in patients $<50$ years of age. Hepatitis $B$ and hepatitis $C$ were the main cause of liver cirrhosis in our cohort (86.7\%), and their natural history is closely related to age. Thabut $\mathrm{D}$ et al. ${ }^{[18]}$ analyzed 891 patients with HBV and/or HCV in the prospective cohort from 35 centers in France, and found that age, an absence of viral suppression, and an unfavorable Baveno VI status were independently associated with poorer overall survival. It is reasonable and necessary to predict the prognosis of patients with cirrhosis by age stratification. Therefore, we argued that age could be a risk stratification indicator for HRV in patients with compensated cirrhosis. We proposed and validated the formulated screening strategies based on stratification by age. We have validated the B6C and EB6C in the entire cohort and the age-stratified subgroup (Supporting Table S2). The number of EGDs avoided by using the $\mathrm{B} 6 \mathrm{C}$ was relatively low, and $57 \%$ of patients were misclassified using this rule. The EB6C enhanced the number of spared EGD in the entire cohort. But the risk of missing HRV increased to $6.4 \%$ in patients $\geq 50$ years of age. Therefore, the EB6C was not safe in older patients who had a greater risk of HRV.

Regardless of age, the screening criteira for MB6C were milder than those for $\mathrm{B} 6 \mathrm{C}$. Consistent with our expectations, the screening criteria for $\mathrm{MB} 6 \mathrm{C}$ in patients age $<50$ were milder than in patients $\geq 50$ years of age. Augustin S et al. ${ }^{[19]}$ found that the rule of PLT $>100 \times 10^{9} / \mathrm{L}$ and $\mathrm{LS}<30 \mathrm{kPa}$ would increase the risk of missing an HRV to $8.7 \%$, but we found that this broader classification rule works well in patients < 50 years old, and increases the avoidance of EGD sharply $(69.4 \%$, nearly twice of B6C (36.8\%)), and the risk of missing HRV just slightly increases (1.1\%). For patients $\geq 50$ years old, the more stringent screening strategy of PLT greater than $125 \times 10^{9} / \mathrm{L}$ and LS lesser than $20 \mathrm{kPa}$ was adopted to keep the risk of missing $\mathrm{HRV}<5 \%$ while the number of EGDs avoided increased by $12.1 \%$ compared to the B6C (Supporting Table S2; Table S3). 
The burden of chronic liver disease ranks high around the world, but TE has not been widely implemented in many institutions, which limits the clinical use of the B6C. We have provided a screening strategy that did not require LS, offering doctors in primary hospitals a simple method to assess and screen HRV. The ultrasound is the most commonly used liver imaging technique for its non-invasive, inexpensive, real-time imaging and repeatability. It is available in most medical institutions, making it the best alternative to LS. The spleen area was proposed and classified by Ishibashi H et al. ${ }^{[20]}$ in 1991 . Their study showed that the SA correlated well with the volumes of resected spleens, and the guideline ${ }^{[15]}$ pointed out that $S A>45$ $\mathrm{cm}^{2}$ is a sign of portal hypertension. The $S A$ is a promising tool, it was independently associated with the presence of HRV in our study, so we combined it with the PLT to build the alternative criteria. AB6C retained the PLT cut-off values of MB6C, and $55 \mathrm{~cm}^{2}$ and $44 \mathrm{~cm}^{2}$ were selected as the SA cut-off values for patients aged $<50$ and $\geq 50$ years, respectively. They could still achieve similar efficacy to MB6C in ruling out HRV (Supporting Table S2; Table S3). In total, AB6C safely avoided 49.2\% EGD in the entire cohort $(n=1188)$ regardless of age.

The MB6C and AB6C formulated for patients in different age stratifications have been internally verified and have shown good performance in the entire cohort. Using these strategies may ensure maximum safety in patients with CLC. Overall, the performance of the MB6C is slightly better than that of the AB6C, while both of them are better than the $\mathrm{B} 6 \mathrm{C}$ and safer than the $\mathrm{EB} 6 \mathrm{C}$.

This study had a few limitations: as this was a retrospective study, the data was obtained from medical records. These new criteria need external verification. Finally, the examinations were performed by different operators, but they had all been professionally trained. This problem is not uncommon in clinical research.

In summary, our study demonstrates that the Baveno VI criteria for avoiding EGD in patients with CLC can be safely optimized, and LS can be replaced by the spleen area. With the MB6C and AB6C based on age, the number of EGD savoided by patients were more than $60 \%$ and nearly $40 \%$ for patients aged $<50$ and $\geq 50$, respectively. In total, $\mathrm{MB} 6 \mathrm{C}$ and $\mathrm{AB} 6 \mathrm{C}$ safely avoided about $50 \%$ EGDs in the entire cohort.

\section{Declarations}

\section{Conflict of Interest statement:}

All authors declare that they have no conflict of interest related to this paper.

\section{Financial funding statement:}

This investigator-initiated trial received support by Tianjin Key Medical Discipline(Specialty) Construction Project and Tianjin Health Science and Technology Project (No. TJWJ2021MS034 and No.

TJWJ2021ZD010).

\section{Authors' contributions:}


Study concept and design:Jia Li; Supervision of the study: Jia Li and Lili Zhao; Data collection: Lili Zhao, Ting Wang, Chunxia Guo and all authors; Analysis and interpretation of data:Ting Wang; Drafting of the manuscript: Lili Zhao and Ting Wang; All authors revised the manuscript critically and approved the version to be published.

\section{Clinical trial number:}

ChiCTR-DDD-17013845.

\section{References}

1. Garcia-Tsao G, Abraldes JG, Berzigotti A, et al. Portal hypertensive bleeding in cirrhosis: Risk stratification, diagnosis, and management: 2016 practice guidance by the American Association for the study of liver diseases. Hepatology. 2017;65(1):310-335.

2. North Italian Endoscopic Club for the Study and Treatment of Esophageal Varices.Prediction of the first variceal hemorrhage in patients with cirrhosis of the liver and esophageal varices. A prospective multicenter study. N Engl J Med. 1988;319(15):983-989.

3. de Franchis R; Baveno V Faculty. Revising consensus in portal hypertension: report of the Baveno V consensus workshop on methodology of diagnosis and therapy in portal hypertension. J Hepatol. 2010;53(4):762-768.

4. Primignani M, Carpinelli L, Preatoni P, et al. Natural history of portal hypertensive gastropathy in patients with liver cirrhosis. The New Italian Endoscopic Club for the study and treatment of esophageal varices (NIEC). Gastroenterology. 2000;119(1):181-187.

5. de Franchis R; Baveno VI Faculty. Expanding consensus in portal hypertension: Report of the Baveno VI Consensus Workshop: Stratifying risk and individualizing care for portal hypertension. J Hepatol. 2015;63(3):743-752.

6. Jangouk P, Turco L, De Oliveira A, Schepis F, Villa E, Garcia-Tsao G. Validating, deconstructing and refining Baveno criteria for ruling out high-risk varices in patients with compensated cirrhosis. Liver Int. 2017;37(8):1177-1183.

7. Maurice JB, Brodkin E, Arnold F, et al. Validation of the Baveno VI criteria to identify low risk cirrhotic patients not requiring endoscopic surveillance for varices. J Hepatol. 2016;65(5):899-905.

8. Gaete MI, Díaz LA, Arenas A, et al. Baveno VI and Expanded Baveno VI criteria successfully predicts the absence of high-risk gastro-oesophageal varices in a Chilean cohort. Liver Int. 2020;40(6):14271434.

9. Augustin S, Pons M, Maurice JB, et al. Expanding the Baveno VI criteria for the screening of varices in patients with compensated advanced chronic liver disease. Hepatology. 2017;66(6):1980-1988.

10. Moctezuma-Velazquez C, Saffioti F, Tasayco-Huaman S, et al. Non-Invasive Prediction of High-Risk Varices in Patients with Primary Biliary Cholangitis and Primary Sclerosing Cholangitis. Am J Gastroenterol. 2019;114(3):446-452. 
11. Zheng KI, Liu C, Li J, et al. Validation of Baveno VI and expanded Baveno VI criteria to identify highrisk varices in patients with MAFLD-related compensated cirrhosis. J Hepatol. 2020;73(6):1571-1573.

12. Petta S, Sebastiani G, Bugianesi E, et al. Non-invasive prediction of esophageal varices by stiffness and platelet in non-alcoholic fatty liver disease cirrhosis. J Hepatol. 2018;69(4):878-885.

13. Tsochatzis EA, Bosch J, Burroughs AK. Liver cirrhosis. Lancet. 2014;383(9930):1749-1761.

14. Tajiri T, Yoshida H, Obara K, et al. General rules for recording endoscopic findings of esophagogastric varices (2nd edition). Dig Endosc. 2010;22(1):1-9.

15. Berzigotti A, Piscaglia F. Ultrasound in portal hypertension--part 1. Ultraschall Med. 2011;32(6):548571.

16. Berzigotti A, Seijo S, Arena U, et al. Elastography, spleen size, and platelet count identify portal hypertension in patients with compensated cirrhosis. Gastroenterology. 2013;144(1):102-111.e1.

17. Berger A, Ravaioli F, Farcau O, et al. Including Ratio of Platelets to Liver Stiffness Improves Accuracy of Screening for Esophageal Varices That Require Treatment. Clin Gastroenterol Hepatol. 2021;19(4):777-787.e17.

18. Thabut D, Bureau C, Layese R, et al. Validation of Baveno VI Criteria for Screening and Surveillance of Esophageal Varices in Patients With Compensated Cirrhosis and a Sustained Response to Antiviral Therapy. Gastroenterology. 2019;156(4):997-1009.e5.

19. Augustin S, Pons M, Maurice JB, et al. Expanding the Baveno VI criteria for the screening of varices in patients with compensated advanced chronic liver disease. Hepatology. 2017;66(6):1980-1988.

20. Ishibashi H, Higuchi N, Shimamura R, Hirata Y, Kudo J, Niho Y. Sonographic assessment and grading of spleen size. J Clin Ultrasound. 1991;19(1):21-25.

\section{Figures}




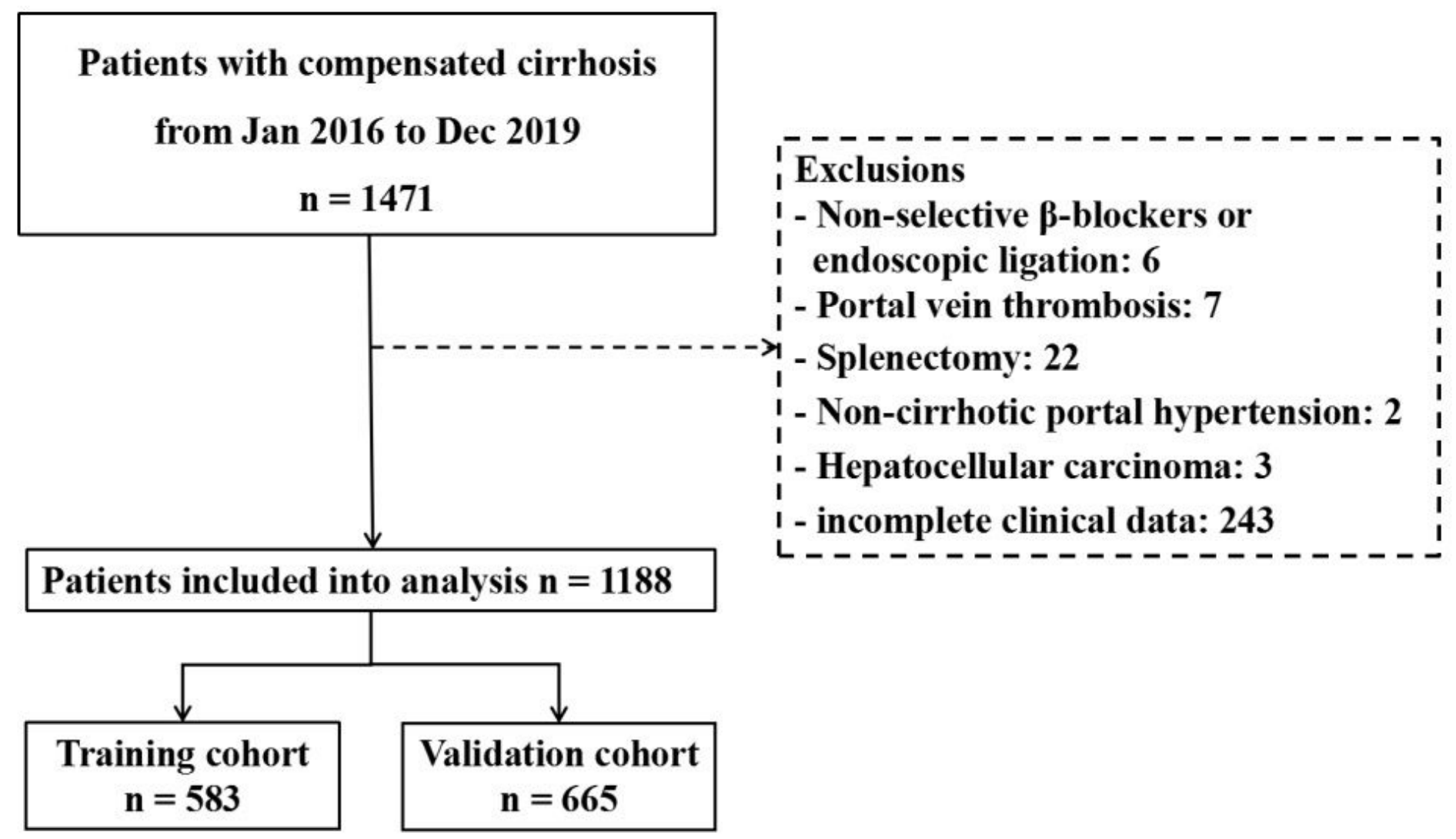

Figure 1

Flow chart of the study population 


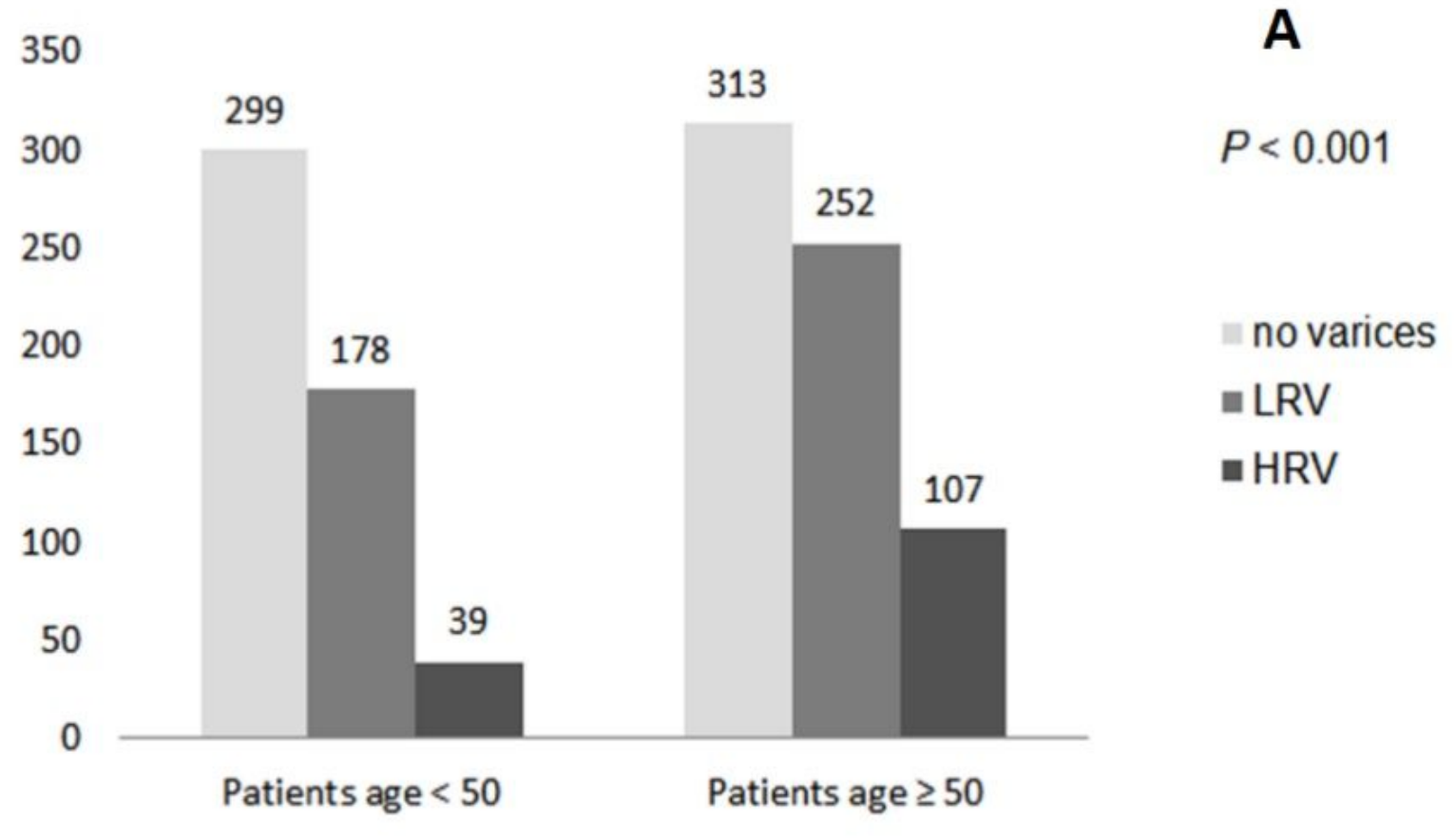

A

$$
P<0.001
$$

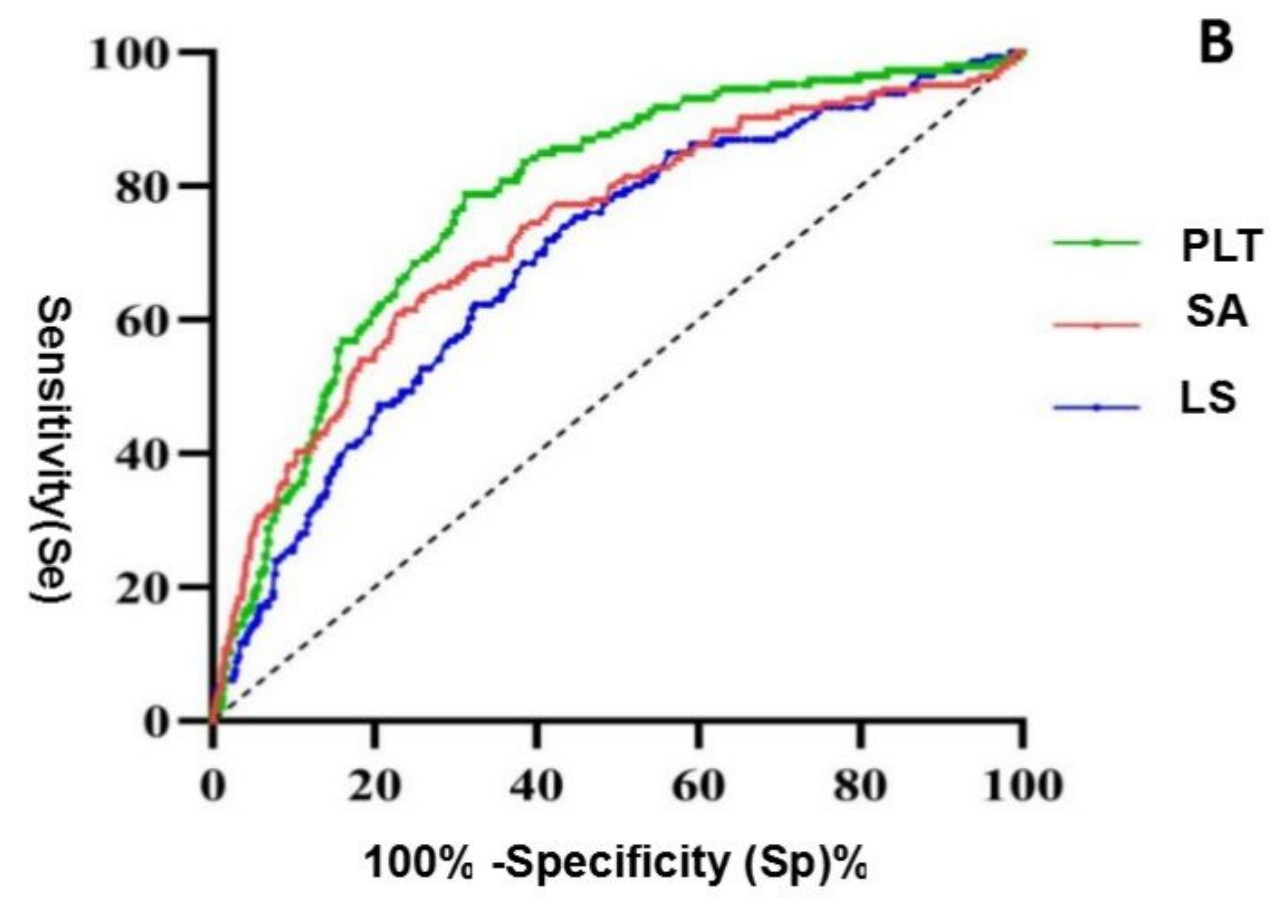

Figure 2

Age, PLT, SA and LS for predicting HRV

Abbreviations: LRV, Low-risk varices; HRV, High-risk varices;PLT, Platelet count $\left(\times 10^{9} / \mathrm{L}\right)$; LS, Liver stiffness $(\mathrm{kPa})$; $\mathrm{SA}$, Spleen area; 
A: Prevalence of varices and high-risk varices in age-related subgroups of the entire cohort. The risk of $\mathrm{HRV}$ in patients $\geq 50 \mathrm{y}$ was 2.387 times higher than that in patients $<50 \mathrm{y}$.

B: Efficacy of PLT, LSM and spleen area in predicting HRV. There was no statistical difference between PLT, SA and LS.So, SA could replace LS for build new criteria for predicting HRV.

The entire cohort

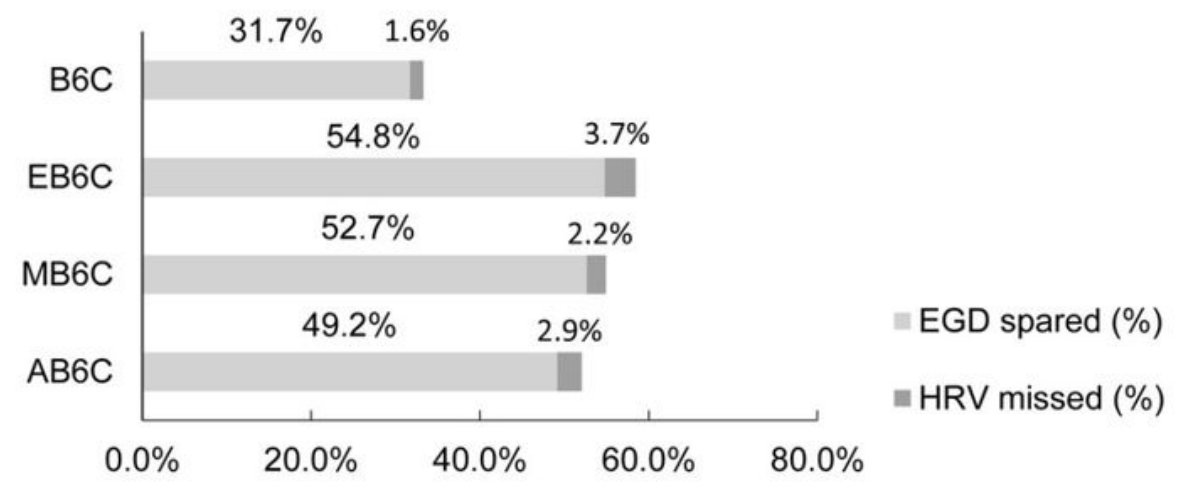

Group age $<50$ in the entire cohort

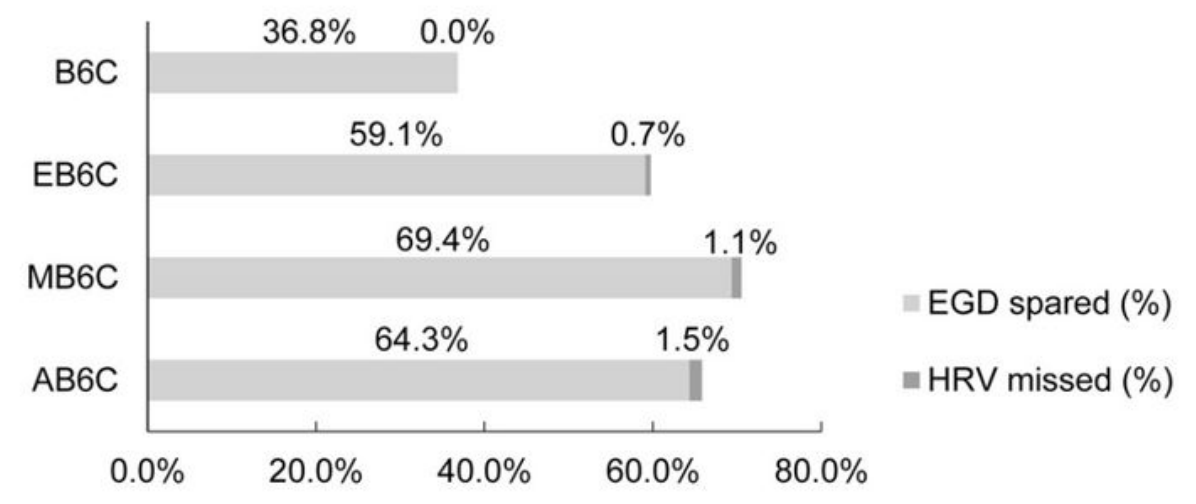

Group age $\geq 50$ in the entire cohort

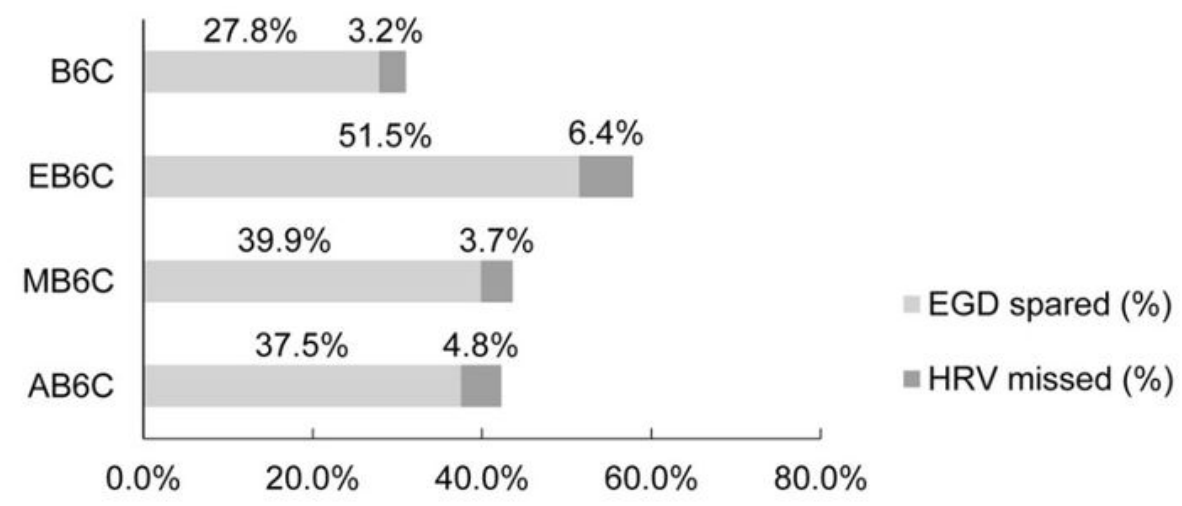

Figure 3 
Comparison of the performance of $\mathrm{B} 6 \mathrm{C}, \mathrm{EB} 6 \mathrm{C}, \mathrm{MB} 6 \mathrm{C}$, and $\mathrm{AB} 6 \mathrm{C}$ in ruling out of $\mathrm{HRV}$ in the entire cohort and age-related subgroups

Abbreviations: B6C, Baveno VI criteria; EB6C, Expanded Baveno VI criteria; MB6C, Modified Baveno VI criteria; AB6C, Alternative Baveno VI criteria; EGD, sophagogastroduodenoscopy; HRV, High-risk varices;

\section{Supplementary Files}

This is a list of supplementary files associated with this preprint. Click to download.

- Supplementarymaterials.docx 